\title{
Learning Relative Clauses by Iranian EFL Learners: Task-Based Activities Versus Teacher-Focused Activities
}

\author{
Maryam Bahrami (corresponding author) \\ Department of English, Najafabad Branch, \\ Islamic Azad University, Najafabad, Iran \\ E-mail: M.bahrami3000@yahoo.com
}

S. Ketabi, PhD

ketabi@,fgn.ui.ac.ir

Doi: 10.5901/mjss.2013.v4n4p83

\begin{abstract}
Task-Based Approach (TBA) has gained its popularity in the field of language pedagogy since the last decade of the 20th century and significant scholars have joined the discussion to increase the amount of analytical studies on this issue. This study attempts to investigate the topic of Task-based activities and learning relative clauses by Persian EFL learners. To carry out this study, first, a general proficiency exam (IOPT test) was administered among all students who were supposed to be at intermediate level at Sobhe Sadegh Higher Education Institute. Afterwards, the participants were divided into three homogeneous groups, and a pretest was given to them. After the administration of the pretest the treatment was performed. The subjects of the two experimental groups were given task sheets, which gave them the requisite information and terminology regarding relative clauses and relative pronouns requiring them to generate two rules concerning the omission of relative pronouns, and to combine pairs of sentences to make a single sentence with a relative clause. The two experimental groups received almost the same treatment, the only difference being that in one group there was teacher feedback on the students' solutions to tasks whereas in the other there was no such feedback. The third group, considered as the control group, which was working on a reading assignment, received a conventional teacher-fronted grammar lesson in English by the researcher. After two weeks the posttest was given to the subjects again. The present study also provides the theoretical background to Task-Based Language Learning (TBLL), a framework for TBLL with explanations, and factors to consider when implementing task-based language learning.
\end{abstract}

Key Words: Learning Relative clause, Task, Activity, Task-based Teaching.

\section{Introduction}

in the late 1970s, with the rise of communicative methodology of language teaching, the role of grammar instruction in second language learning lost its importance, and it was even suggested that teaching grammar was not only unhelpful but might also be detrimental. However, recent research has demonstrated the need for formal instruction for learners to attain high levels of accuracy. This has caused grammar teaching to regain some of its significance, and its role in second language acquisition has become the focus of much current investigation (Nassaji, and Fotos, 2004, p. 214).

Task-based language teaching/ learning is a new teaching method. "Task" is a special term in language teaching and is different from language exercise. It has its specific features, forms and teaching steps. There are varieties of tasks in English teaching, but the focus of every task is on solving a communicative problem, which has some connections with a real world of learners' lives and learning experience, and which can arouse learners' interest and participation.

Task-based language learning involves students in performing tasks relevant to their future profession, and increases learners' motivation. However, it does not emphasize linguistic issues in the primary stages. Language analysis is incorporated only after learners have performed a task and this analysis depends on their needs, which become apparent only after performance. Task based language learning seems to favor meaningful use of language and can promote autonomous learning. Besides, it implies meaningful use of language and provides unthreatening environment for learning. However, due to uncertainties in assessing learning outcomes, this approach has not been universally accepted by English language practitioners and linguists. 
Among the very many aspects of English grammar, relative clauses are syntactic complex structures that include embedding and movement of a noun phrase from within the embedded clause. It is well documented that children have difficulties in producing and understanding constructions that involve wh-movements. Relative clauses are derived by movement either from a subject or an object position.

\section{Literature Review}

The following are some recent researches done to investigate Task based Language Learning/Teaching as well as some recent definitions of the term 'task' postulated by some scholars.

Discussing from a psycholinguistic perspective, Eliss (2003) believes that "... a task is a device that guides learners to engage in certain types of information-processing that are believed to be important for effective language use and/or for language acquisition from some theoretical standpoint". Ellis (2003) also provides a composite definition which is as follows:

"A task is a work-plan that requires learners to process language pragmatically in order to achieve an outcome that can be evaluated in terms of whether the correct or appropriate propositional content has been conveyed."

According to Nunan (2006) a task is "a piece of classroom work involving learners in an understanding, directing, producing or interacting way in the target language while the students' attention is focused on activating their grammatical knowledge in order to express meaning, and in which the aim is to express meaning rather than to manipulate form." Two other scholars, Samuda and Bygate's (2008) also define a task as " a holistic activity which engages language use in order to achieve some non-linguistic outcome while meeting a linguistic challenge, with the overall aim of promoting language learning, through process or product or both" (p. 69).

Contemori \& Garrafa (2010) studied comprehension and production of relative clauses of preschool-aged Italian children, typically developing (aged 3; 7 to $3 ; 10$ and $4 ; 5$ to $5 ; 5$ ) and SLI children (four children aged 4;5 to $5 ; 9$ ). Comprehension of relative clauses was tested with a binary picture comprehension task adapted from Friedmann and Novogrodsky (2004). In another study, Jaccobs and Navas (2000) investigated the clarity of three task categories for a group of Philippine teachers of English as a second language working in the Philippines.

Ozan et al. (2005) believe that at the traditional education system, the students have the chance to make some practices at the related lessons. But it is clear that if the related educational practices are not put together, they will not be successful. With the help of Task Based Learning, the education system aims to adapt students to the working conditions rapidly by getting these related practices together (p. 135).

In a study of Japanese EFL learners, Takimoto (2009) found that English polite request forms could be effectively targeted by different input-based tasks and that completing these tasks resulted in learners improving their pragmatic proficiency as measured in pre-, post- and follow-up tests (p. 120).

Learning grammatical structures are of great concern for most learners, teachers and syllabus designers among which relative clauses are of high importance. Based on the brief explanation provided on the importance of devising new and relevant discourse and pedagogy especially in the area of teaching/learning grammatical tasks, it seems to the researcher that few studies have been done at least concerning the teaching/learning of relative clauses in the context of Iran at the university level.

Richards and Rodgers (2011) believe that authentic materials are an important part of task-based activities and can come from a wide variety of sources (p. 13).

\section{Statement of the Problem}

A number of studies including Jaccobs and Navas (2000), Ellis (2003), Al Nashash (2006), Aljarf (2007), Birjandi and Ahangari (2008) , Takimoto (2009), Richards and Rodgers (2011) have been conducted to determine whether Taskbased Language Teaching methodology has any significant impact on students' learning or not. Despite the fact that such studies have been done, the review of the previous literature suggests that the number of studies on the application of this methodology is not considerable at least in the Iranian context. It seems that more studies should be done to further illustrate it.

Therefore, to contribute to the developing literature in the field, this research to investigating the aforementioned issue among Iranian EFL learners with 90 female intermediate EFL students studying English at Sobhe Sadegh Higher Education Institute selected on a non-random basis by applying a general English placement test (Interchange Placement 
Test- Interchange Placement and Evaluation Package, Third Edition-Cambridge University Press 2005- hereafter called IOPT) among over $120 \mathrm{EFL}$ students.

\subsection{Research Questions:}

This study has made an attempt to seek appropriate answers to the following questions:

1. Does Task-based approach have the same effect as traditional approach in teaching grammar (specifically relative clauses) to Iranian EFL learners?

2. Does providing feedback by teachers produce better results than not providing it in grammar classes taught through task-based approach?

\subsection{Research Hypothesis:}

Accordingly, based on the above questions, the following hypotheses are formulated for the study in hand:

1. Task-based approach has the same effect as traditional approach in teaching grammar (specifically relative clauses) to Iranian EFL learners.

2. Providing feedback by teachers does not produce better results than not providing it in grammar classes taught through task-based approach.

\section{Methodology}

\subsection{Participants}

The participants were 90 female intermediate EFL students studying English at Sobhe Sadegh Higher Education Institute selected on a non-random basis by applying a general English placement test (Interchange Placement Test- Interchange Placement and Evaluation Package, Third Edition-Cambridge University Press 2005- hereafter called IOPT) among over $120 \mathrm{EFL}$ students considered to be at the intermediate level, in order to make sure that the participants were homogeneous with regard to their language proficiency. Those whose scores in the test were from 37 to 49 (i.e. rating 78) were considered the intermediate-level participants of this study. They had received instructions on English language for about 2 years in that institute before taking part in this study. They were studying Interchange series (3rd edition). All of the participants were native speakers of Persian, and they used English as a foreign language for general purposes. Their age ranged from 20 to 30 .

\subsection{Materials/Instruments}

The materials utilized or constructed for the present study included the following:

\subsubsection{IOPT}

The IOPT (Interchange Objective Placement Test). In order to identify the English knowledge of the participants, a general English placement test (Interchange Placement Test- Interchange Placement and Evaluation Package, Third Edition-Cambridge University Press 2005) was applied. Each test was composed of 3 sections including the listening section (20 questions), the reading section (20 questions) and the language use section (30 questions). All of the items were multiple-choice questions.

\subsubsection{Task Cards}

The task cards contained a number of grammatical and ungrammatical sentences, illustrating the use of relative pronouns in relative clauses (when relative pronouns could be omitted and when they couldn't be omitted). They specified which sentences were correct and which sentences were incorrect.

\subsubsection{Task Sheet}

The task sheet provided the learners with some basic grammatical information concerning relative clauses and also supplied them with some useful metalinguistic terminology (e.g., relative clauses and relative pronouns). In addition, the 
task sheet contained a number of sentences to be combined into sentences with relative clauses. Finally, it instructed the learners to formulate rules about relative clauses. This task was designed for use in pairs or groups of four learners.

The content of the traditional grammar lesson was identical to the information given on the task sheet and task cards, and took the same amount of time to cover (20 minutes). The teacher wrote the correct and incorrect sentences on the board, asking the students whether the sentences were correct or incorrect. The teacher then provided the answers, and at the end of the lesson, she wrote out the rules concerning relative clauses.

\subsection{Procedures}

To carry out this study, the following procedures were followed: first of all, a general proficiency exam (IOPT test) was administered among all students who were supposed to be at intermediate level in Sobhe Sadegh Higher Education Institute that were chosen on a non-random basis from among those who scored the ratings of 7-8 based on Interchange Placement Test- Interchange Placement and Evaluation Package, (Third Edition-Cambridge University Press 2005).

Then the participants were divided into three homogeneous groups, and a pretest was given to them. After assigning the participants into the three mentioned groups, in order to make sure that the three groups were homogeneous, an ANOVA test was run on their IOPT scores.

Also, in order to ensure the groups' homogeneity regarding grammatical proficiency, the means of the scores of the three groups on the pretest were compared. It was found that the means were close to each other and there weren't any significant difference between the three groups. The pretest was a grammaticality judgment test.

After the administration of the pretest, the researcher carried out the treatment. The subjects of the two experimental groups were given task sheets, which gave the students the necessary information and terminology regarding relative clauses and relative pronouns. It also required them to generate two rules concerning the omission of relative pronouns, and to combine pairs of sentences to make a single sentence with a relative clause.

The students performed the task in groups of three. Each member of the group had a task card with five sentences marked correct or incorrect which she had to read to the other group members. Therefore, the students had to exchange the information on their task cards in order to agree on the results. The subjects had to report the rules they had formulated.

The two experimental groups received the same treatment, except that in one group teacher feedback was absent, while the subjects of the other group received feedback on their solutions to the tasks.

The traditional, teacher-fronted grammar lesson was presented in English by the researcher to the third group. The third group served as the control group and worked on a reading assignment. After two weeks the posttest was given to the subjects again.

\subsection{Data Analysis}

Having collected all the data for describing and analyzing the information, using the SPSS software version 16, the principles of descriptive statistics were applied in order to identify and describe the data. The measures of mean and standard deviation were calculated. Inferential statistics were applied to test the proposed hypotheses. The means of the two groups were compared by the application of a t-test. Moreover, the data were analyzed qualitatively and the answers were considered with scrutiny to find out the answers to the research questions formulated for the purpose of this study.

\section{Results and Discussion}

\subsection{Results}

\subsubsection{Investigating the First Research Question}

As it can be seen in table 5.1, the means of the three groups are very close to each other; however, it was decided to apply a one-way ANOVA to make sure the differences were not statistically significant. Table 5.2 depicts the results of the ANOVA. (See appendix 1).

By studying the results in Table 5.2, one can easily see that the amount of F-observed (F-observed $=.130$ ) is not statistically significant $(p=.879)$. Therefore, it can be claimed that the three groups were homogeneous with regard to their grammatical knowledge of English. (See appendix 1) 
After completing the experiment and administering the posttest, once again the participants' performances were compared. Table 5.3 reveals the descriptive statistics for the posttest.

By examining Table 5.3, it could be realized that the means of the three groups are different. In order to understand whether these differences are statistically significant or not, another one-way ANOVA was employed. Table 5.4 presents the results of this ANOVA. (See appendix 1 ).

Table 5.4 clearly shows that the amount of F-observed (F-observed= 57.838 ) is significant at the probability level of $p=.000$ which denotes a statistically significant amount; therefore, it can be said that the three groups performed differently on the posttest. In order to find the exact place(s) of difference(s), a Scheffe post hoc test was run. Table 5.5 indicates the results of this test. (See appendix 1).

According to Table 5.5 , the following results can be obtained (appendix 1):

1. Experimental group 1 performed better than control group

2. Experimental group 2 performed better than control group

3. Experimental group 2 performed better than Experimental group 1

Therefore, based on the analysis obtained in response to the formulated hypothesis, the first null hypothesis can safely be rejected, and it can be claimed that task-based grammar teaching does produce better results than traditional grammar teaching.

\subsubsection{Investigating the Second Research Question}

The purpose of the second hypothesis was to see if teacher's feedback had any effect on the students' learning the task. In order to do so, the results of the posttest for the two experimental groups were compared. By referring back to Table 5.3 , it can be seen that the two groups' means are different. Moreover, Table 5.5 clearly shows that the difference between the two experimental groups is statistically significant $(p=.000)$. Therefore, it can be concluded that the teacher's feedback did have a positive effect on the students' grammatical performance, in this case, earning relative clauses. As result, the second null hypothesis can also be safely rejected.

\subsection{Discussion}

The rejection of the first null hypothesis has led the researcher to conclude that Iranian EFL intermediate learners can learn L2 grammatical rules including relative clauses more effectively through task-based approach. In other words, the traditional approach is not as effective as the task-based approach in students' learning of a difficult L2 grammatical rule.

Also the rejection of the second null hypothesis has led the researcher to accept the idea that teacher feedback is effective in the students' learning of an L2 rule. As a response to the second research question it can be stated that Iranian female EFL intermediate students can learn relative clauses more effectively by a task-based approach when teacher is present. In order to prevent the teacher from giving formal instruction about the grammatical point, the feedback which the task group subjects received was on how effectively they had performed the task. It was either a positive or a negative, response to their solutions to the task, and no instruction regarding relative clauses was given.

\section{Conclusion}

In order to familiarize students with the performance and group work, in the present study, students were required to perform a grammar task; identical to the task performed in. this study. The problematic grammatical feature selected for this task was dative verbs and students were required to perform the task in groups.

The study in hand was carried out to find the effects of providing feedback by teachers on producing better results than not providing it in grammar classes taught through task-based approach. The results of the study showed that there was an improvement on learning relative clauses through task-based activities vs. teacher-focused activities after they were given exposure to a few grammar lessons in the class. It was observed that through task-based activities the students were enthusiastic, and learned relative clauses more effectively. So it can be claimed that according to the studies mentioned earlier and the results obtained through data analysis made on the formulated hypotheses, task-based learning represents an important approach in teaching EFL. It supports learners to learn and develop their English language competence effectively.

The results of the present study lend support to the claim that L2 learners at the intermediate level are able to increase their knowledge of a second/foreign language rule by completing an assigned grammar task. The results also suggest that teacher feedback on learners' solutions to the grammar task is effective in promoting their knowledge of the 
target language rule. Learners performing the task have the opportunity to learn about grammar while taking part in communication centered on an exchange of information.

\section{References}

Adani, F. (2010). Re-thinking the Acquisition of Relative Clauses in Italian: Towards a grammatically-Based Account. Journal of Child Language, in press.

Aljarf, R. (2007). From Reticence to Fluency: The Effect of TBLT on Students' Speaking Ability. Retrieved July18, 2009, From: http:// www. tblt. Download /al-jarf-poster 1. Pdf

Al Nashash, A. H. (2006). Designing a Task- Based Program and Measuring its Effect on Oral and Written Communicative Skills Among Jordanian EFL Secondary Stage Students. Unpublished Doctoral Dissertation, Amman Arab University.

Birjandi, $P$, and Ahangari, S. (2008). Effects of Task Repetition on the Fluency, Complexity and Accuracy of Iranian EFL Learners' Oral Discourse. Retrieved December, 17, 2009, from: http://www.asian-efl-journal.com/site_map_2008.php

Contemori, C., \& Garraffa, M. (2010). Comparison of Modalities in SLI Syntax: A Study on the Comprehension and Production of NonCanonical Sentences. Lingua, 120(8), 1940-1955.

Ellis, R. (2000). Task-Based Research and Language Pedagogy. Language Teaching Research, 4 (3), 193-200.

Ellis, R. (2003). Task-Based Language Learning and Teaching. Oxford: Oxford University Press.

Friedmann, N., and Novogrodsky, R. (2004). "The Acquisition of Relative Clause Comprehension in Hebrew: A study of SLI and Normal Development," Journal of Child Language 31, 661-681.

Jaccobs, G. and Navas, E. (2000).Designing Communicative Task for College English Teachers. Retrieved October, 30, 2008,from: www. asian-EFL-journal. Com/thesis_wand_cheng_jun.Pdf.

Nassaji, H. \&Fotos, S. (2004). Current Developments in Research on the Teaching of Grammar. Annual Review of Applied Linguistics (2004) 24, 126B145. Printed in the USA. Copyright 82004 Cambridge University Press

Nunan, D. (2006). Task-Based Language Teaching in the Asian Context: Defining 'Task'. 10. Asian EFL Journal 8 (3). Online documents at URL http://www.asian-efl-journal.com/Sept_06_dn.php. [15.12.2006]

Richards, J. and Rodgers, T.(2011). Approaches and Methods in Language Teaching (Second Edition). New York, NY: Cambridge University Press.

Samuda, V., \& Bygate, M. (2008). Tasks in Second Language Learning. Houndsmills,Hampshire: Palgrave Macmillan.

Takimoto, M. (2009). The Effects of Input-Based Tasks on the Development of Learners' Pragmatic Proficiency. Applied Linguistics, $30 / 1,1-25$.

\section{Appendix 1}

Table 5.1: Descriptive Statistics for the OPT

\begin{tabular}{llllll}
\hline Group & N & Mean & SD & Min & Max \\
\hline Control & 30 & 68.60 & 2.094 & 65 & 75 \\
Experimental 1 & 30 & 68.70 & 2.395 & 65 & 75 \\
Experimental 2 & 30 & 68.90 & 2.468 & 65 & 75 \\
\hline
\end{tabular}

Table 5.2: The Results of the One-way ANOVA for the OPT

\begin{tabular}{llllll}
\hline Source & SS & df & MS & F & Sig. \\
\hline Between Groups & 1.400 & 2 & .700 & .130 & .879 \\
Within Groups & 470.200 & 87 & 5.405 & & \\
Total & 471.600 & 89 & & & \\
\hline
\end{tabular}

Table 5.3: Descriptive Statistics for the Posttest

\begin{tabular}{llllll}
\hline Group & N & Mean & SD & Min & Max \\
\hline Control & 30 & 9.73 & 2.116 & 3 & 14 \\
& \multicolumn{2}{c}{$\begin{array}{c}0 \\
\text { 8 }\end{array}$}
\end{tabular}




\begin{tabular}{llllll} 
Experimental 1 & 30 & 12.40 & 1.102 & 10 & 15 \\
Experimental 2 & 30 & 14.37 & 1.650 & 11 & 17 \\
\hline
\end{tabular}

Table 5.4: The Results of the One-way ANOVA for the Posttest

\begin{tabular}{llllll}
\hline Source & SS & df & MS & F & Sig. \\
\hline Between Groups & 324.467 & 2 & 162.233 & 57.838 & .000 \\
Within Groups & 244.033 & 87 & 2.805 & & \\
Total & 568.500 & 89 & & & \\
\hline
\end{tabular}

Table 5.5: The Results of the Scheffe Post Hoc Test

\begin{tabular}{llll}
\hline Group & Group & Mean Difference & Sig. \\
\hline Control & Experimental 1 & $-2.67^{*}$ & .000 \\
& Experimental 2 & $-4.63^{*}$ & .000 \\
\hline Experimental 1 & Control & $2.67^{*}$ & .000 \\
& Experimental 2 & $-1.97^{*}$ & .000 \\
\hline Experimental 2 & Control & $4.63^{*}$ & .000 \\
& Experimental 1 & $1.97^{*}$ & .000 \\
\hline
\end{tabular}


